\title{
Teachers' Perception on School Health Services
}

Arjun Prasad Poudel*

\begin{abstract}
Teaching health and physical education by qualified teachers can support the promotion of health among school children. In Nepal, school health programme has not been run effectively as health and any subject teachers teach physical education subject. On the other hand, government policy makers and school management does not seem serious about this issue. In this context, the study intends to explore perceptions of teachers on students' health promotion through school health services. This study was based on qualitative research design specifically phenomenological approach. Qualitative data were collected from twelve purposefully selected teachers of six different community schools of Kathmandu using in- depth interview technique. The collected data were analyzed by applying thematic approach. The study collected perception of Health and Physical Education (HPE) teachers regarding school health services, health promotive activities, water, sanitation and hygiene that play crucial role to promote healthy behaviour of students. In their perception, school health services should be provided to promote students' health, control the epidemics and communicable diseases and to create healthy school environment. In their perception, child friendly school creates an open-learning environment and keeps students mentally sound, creative and well-motivated in learning. Based on the findings of the study, it can be concluded that teachers' perception on school health programme is fairly satisfactory. However, their health activities are limited within the classroom practices and theoretical notions included in the textbook.
\end{abstract}

Keywords: promotion, perception, comprehensive, appraisal, preventive, curative

\section{Introduction}

School health programme refers to those activities that produce healthful environment in the school. It includes school health services, healthful school living, health instruction and school community activities (Keith \& Green, 2004). School health programme provides an opportunity to the students to involve in healthy practices for health care. As the joint committee on health education technology defines, "School health programme is the composite of procedures and activities designed to protect and promote the well-being of students and school personnel. These procedures and activities are organized in school health services providing healthful environment and health education," (Macdonald, 1998, p. 171).

In Nepal, students spend about 200 days in the school in a year (JICA, 2003). They spend almost seven hours per day in school. Their mental and physical health is greatly influenced by their interaction in the school environment.
The school is one of the agencies that could contribute more than any other institution to promote the health of young people and school personnel. The school setting provides an effective means of enhancing young people's health, self-system, life skills and behaviour (WHO, 1997). However, the status of health of school children in Nepal is not well understood. Nor the school is concerned with children's health because its priority goes in academic matters. The impact of health status to the learning achievement is getting less attention (Nutritional Strategy, 2006).

Different literature and research findings have shown some gaps regarding the meaning of health promotion, teachers' perceptions about it and its implementation through the school health programme for promoting health status of the pupils. In this study, I have made an attempt to trace out these gaps by examining teacher's perception and attitude towards the school health promotion through the school health programme in Nepal.

* Teaching Assistant, Central Department of Health and Population Education, TU, Kirtipur

C) 2018HEAN JOURNAL OF HEALTH PROMOTION

Vol. 6, June 2018 


\section{Methods}

The phenomenological approach is often referred to as one of the main traditional approaches in the qualitative paradigm (Creswell, 2007). It is a way of examining peoples' lived experiences to ascertain critical truths about reality and study phenomena which were subjective to individuals (Parahoo, 2006). This study was based on qualitative research design specifically phenomenological approach. I collected qualitative data from twelve purposefully selected teachers of six different community schools of Kathmandu using in-depth interview technique. Thematic analysis was carried out for the interpretation of data. Braun and Clarke (2006) define thematic analysis as a qualitative analytic method for identifying, analysing and reporting patterns (themes) within data. The collected data were analyzed by applying thematic approach and considering research questions. In this study, I followed all the ethical considerations. Hence I was honest on the whole ethical procedure of the study. I always established good rapport with research participants and I was fully convinced that they believed me. Then I found that informants were highly motivated to share their views.

\section{Result and Discussions}

\section{Teachers' perceptions on school-health services}

School health service is a service-oriented programme that is implemented to evaluate students' health status, to identify health related problems, to inform the guardians about the health problems of children, to adopt the measures of controlling disease and to suggest effective means of maintaining healthy life of the students (UNICEF, 2011).

On the basis of the information obtained from the discussion about the perceptions of teachers on school-health programme, it is examined that school health programme is a health service that can be provided in a school. It includes improvements in health services, and diagnostic health services. The majority of the teachers agreed on this fact. One of the teachers said, In my opinion, school health services refer to an appraisal of the health of the members of school family, adopting the measures to control the various accidents, providing first aid treatment, hospitalizing the patients in case of massive accidents, keeping the existing health status of individuals safe and conducting the necessary activities to improve the healthy life of students."

The view of teachers indicates that school health service is an appraisal of pre and post health services to the school children and the members of school family. It is also a process or activity of providing safe environment against accidents, emergency care and first aid treatment through the medical personnel, health teachers, social cadres and so on. Besides, promoting health and providing security to the students are also included under school health service.

Regarding the query on school health service and its aspects, one of the teachers presented a bit different views as: "School health service includes all the health services given in the school; however; you can say the main things are: What is given now? When the students do not have concerns in learning and how can a teacher provide health awareness more than the expectation? We also feel difficulty while teaching the related subject matter. Will we get consistency in exam schedule and comprehensiveness of the events? In our context, it is not possible because we don't have school/subject teacher to manage these school health services." However, the respondent has analyzed and interpreted it thoroughly. Health service centers do not have control over on what to teach in the difficult situations, simply, 
because the teachers do not have the knowledge of subject matter related to the school health services programmers in any schools.

Simply, we can educate the students on how to be sustained in healthy environment and healthy physical activities. However, it is not sufficient to bring change in healthy behavior. We have to focus on practical approaches also. Similarly, school health service is related to the disposal of the unnecessary materials and objects in the classroom. Teachers should educate all the students so, the teachers should be designated as doctors. In the same way, the electronic shocks should be minimized through keeping security in classroom. One can avoid the problems simply with due attention on class management. Can we say teachers and students should be educated for change? The management skills need to be developed among them. We know that a person having knowledge of managing the class can manage all forms of learning behaviours so that those behaviours help the students in their health promotion.

Looking at the above view, it can be said that school health service refers to the services given to promote the health of the students in schools. In such a programme, the school has to give emphasis on the health security of the students than any other services. Similarly, health promotion service is also important. The diagnostic and remedial services can also be conducted in the school but it requires many things including the commitment of school family, guardians, and community health units of school's locality, Ministry of Education, Ministry of Health and other health agencies.

\section{Perceptions on appraisal aspects}

Among all the components of school health services, students' appraisal is one of the important aspects. Health appraisal informs the positive process of school personnel. In fact, health appraisal is not an account of individuals' health status, it is the fusion of individual's health to the need of life (Naidoo \& Will, 2009). While analyzing and interpreting the information obtained from the teachers regarding their cognition on health appraisal and its necessity, a few of them agreed that health appraisal is a process of evaluation and checking-up the health of school family and determining the status of their health. Accepting this point, one of the teachers said, "Health appraisal is an activity of accounting the current level of healthy status of the school children. Similarly, it is also related to know whether there is progress or problem in the students' health, and to the reflection on the ways of overcoming those problems."

In the same way, most of the teachers emphasized the appraisal of nutritional status, observation of ear, nose, eye and teeth, and asking questions related to the problems in stomach and other organs of the students. The voices/responses of most of the teachers clarify that it is essential to make an appraisal of teachers' and students' health in a school. Mainly, the nutritional status of students, the problems related to ear, eye, teeth, and the current health status should be included in appraisal. Such appraisal activities assist to promote the students' health properly in time.

\section{Perceptions on preventive aspects}

It is said that 'prevention is better than cure'. So it is important to pay attention on preventive aspects of health service in schools. The preventive aspects of school health services deal with the attempts made to prevent the children and school personnel from accidents, and various diseases. Moreover, it includes the controlling mechanisms employed to be safe from diseases and probable accidents (JICA, 2010). Out of the discussions made on teacher's perceptions on preventive aspects and their need in school, it has been found that 
preventive aspects are essential to identify and control the infectious problems related to the children, to keep them safe from wounds and accidents or to provide safety education, to prevent them from going downward from their current health status, and to treat and maintain their healthy behaviours.

The majority of the teachers agreed that preventive aspects are important to save the time and expenses related to infrastructure in health management. They are important to avoid the health hazards of the individual students and to make them more aware on their own health. Most of the teachers had similar opinion on preventive aspects. With an agreement on the collective opinions on preventive aspects, one of the teachers said, "Preventive service is more effective than any other services given in the school, in fact. It is because if we adopt preventive measures in school, our students will be safe and healthy. In such a situation, we do not have to treat them; there will be very few chances of accidents in school, and we can reduce the cases of infections in school. Then, isn't it the state of health prevention?"

Regarding the discussions on preventive aspects and their need in school, almost all the teachers had an agreement on 'prevention is better than cure'. It also shows that if we provide the preventive services effectively in school, we become able to minimize the most probable cases of accidents in school, the cases of highly infectious diseases, and the negative effects of health hazards in school. Similarly, preventive health services are the controlling measures of health-related problems. So, it can be concluded that preventive aspects are important for providing better school health services.

\section{Perceptions on remedial aspects}

Among the health services provided in a school, preventive service provides safety activities which are taken as important services and appraisal aspect that makes an appraisal of the student's health status (SCNSA, 2011). It helps to know the current health status of the students.

Similarly, there might be the chances of accidents, wounds and cases of being much worried even in doing preventive activities. In the same way, we can see the sufferings of diseases and notice the problems of the students even in making an appraisal. So if we adopt some remedial measure to keep them safe and secure in health, then they will be the part of remedial services. It means remedial service is for treating the students gently in their health problems.

After analyzing the information obtained from the discussion on the perspectives of remedial service provided in school, and its need and importance, most of the teachers were found holding the view that it is equally important to provide remedial services to the students along with the appraisal and preventive services. They also responded that remedial service includes the attempts to diagnose or remedy the health problems explored from the appraisal. In an agreement with the same opinion, one of the teachers said, In my opinion, it is a misconception that remedial service is provided only by a doctor or nurse. In fact, remedial services are important aspects of school health programme. Remedial service is conducted in accordance with the philosophy of school health programme. In other words, remedial service is a programme for achieving optimal health achievement of each of the students studying in school."

The above statement also justifies that the remedial service does not mean that it should be provided by a doctor or nurse. Rather, it can be provided from the side of teacher or school personnel working in school. If possible, doctors, nurses or health experts can be appointed in school otherwise, the health 
teacher of a school can provide basic remedial service which prevents the students from massive accidents as well.

Regarding the discussion on remedial services, one of the teachers presented a bit different view on it. To quote his statement, In my opinion, the remedial service cannot take place in a school. Who has to provide remedial service and how to do that? Even Health Education subject has been taught by the teacher graduated in other subject? In such a situation, is it right to say teacher can provide remedial service in a school? Doctors are not found in the health post near the schools in rural areas. In such a situation, we have to provide remedial service by hiring a doctor or nurse. So what I would like to say is it is not possible to provide remedial service in schools. Simply, we can provide preventive services in school, i.e. referring the students having health problems to the health post soon. Health posts provide the services, whatever required, to reduce the health hazards. So what should we do here in such a situation?"

On the basis of the analysis of above ideas, it can be said that remedial health service is not exactly identical with the concept of providing medicinal treatment and the treatment given by a doctor in the hospital. In the poor/ developing countries like ours, since there is no provision of first aid treatment in schools, it does not seem effective, relevant or useful for most of the schools. However, as a part of school health service, remedial service can include the services like: providing directions and suggestions to the students who have problematic health, and counseling, guidance and support to the students and guardians who need specific and highly advanced services. In such a case, remedial service can be taken as a service to diagnose the specific health problems. It is for providing counseling to control them and to identify the associated services of health and their proper application.

\section{Perceptions on promotive aspects}

The promotive aspect aids to upgrade or enhance the present condition of children's health. It preserves the current status of health and makes necessary efforts for betterment (HKI, 2009). Most of the teachers in this study agreed that promotive aspect has particular importance for improving the current status of health of the children.

While discussing their perceptions on promotive aspects and its role in promoting the health of school children, the majority of teachers viewed that promotive aspect tends to bring about positive changes on personal health programme, health related knowledge, sanitation of classroom and surrounding environment, creation of healthy learning atmosphere and bringing improvements in the healthy habits of the students. 'Promotive aspect has great importance on health promotion' was the main understanding of all the teachers. Being consistent with this view, one of the teachers said, In my personal view, promotive aspect plays crucial role to promote the health of students and the members of the community. Its effectiveness is quite valuable as well. It is because the students in school are from the community and they spend most of the time in school in reality. In this sense, the activities related to health promotion promote their health; and in the same way it helps for promoting the healthy condition of the society because the students are from the same society and have specific role in social changes. So it has specific importance."

The above view also clarifies that the promotive aspect of the school health service programme held in the school has quite constructive role to preserve the present condition of health of the whole school family and contributes to bring changes for improvement. It also has great 
importance to promote the health of the social members with the health of school family. They should focus on the availability of physical and sports materials in school.

\section{Conclusion}

From the above analysis and interpretation of the data collected so far in this study, it has been concluded that most of the teachers perceived health and physical education as a behavioural discipline that facilitates the application of health related knowledge, skills and ideas in order to promote the healthy status of students and school personnel. Similarly, the health and physical education subject teachers perceived that they need to have a good level of competence in subject matter, training, skills practical and required qualification for teaching health and physical education in school.

It is also concluded that teachers have understanding of remedial health service as the treatment of minor injuries and illness, which in fact includes protective, promotive and curative aspects of students' health. This brings changes to make positive health behaviour of students. Finally, it is concluded that their views are positive on the importance of all forms of school health services in the promotion of students' health.

School health programme is a broader perspective to promote the health status of the students and to develop their healthy behaviour and life style. It is a holistic programme for the health promotion of students and school personnel. Such a programme aims to protect, promote and create healthy learning behaviour of the students which can have long term implications for the development of physically, mentally, socially and morally healthy individuals in the nation. It is a cost effective and highly efficient programme to offer a wide range of opportunities to the students and school staff regarding how they can promote their health.

\section{REFERENCES}

Braun, V., \& Clarke, V. (2006). Using thematic analysis in psychology. Qualitative research in psychology, 3(2), 77-101.

Creswell, J. W. (2003). Research design: qualitative, quantitative, and mixed approaches. Thousand oaks (CA): Sage publications.

HKI. (2009). Progress report on school health for the prevention and control of trachoma February to April 2009. Lalitpur: Helen keller international.

JICA. (2003). Prevalence on anemia and its relevant factors among high school girls of Kathmandu valley. Nepal.

JICA. (2010). Baseline survey on school health and nutrition project of Sindhupalchok and Syangja district. Kathmandu: School health and nutrition project, JICA

Keith, T. \& Green, J. (2004). Health promotion: Planning strategies. London: Sage publications.

Mac Donald, T.H. (1998). Rethinking health promotion: A global approach. London: routledge.

Ministry of education and sports and ministry of health and population. (2006). National school health and nutritional strategy Nepal. Government of Nepal, Kathmandu.

Naidoo, J. \& Will, J. (2009). Health promotion: Foundation for practice. London Bailliere Tindall.

Parahoo, K. (2006). Nursing research: Principles process and issues (2nd Ed.). London: Palgrave ma millan.

SCNSA. (2011). Sanitation and hygiene master plan. Kathmandu: Government of Nepal, Steering committee for national sanitation action (SCNSA)

UNICEF. (2011). A case study linking investment to reality: WASH in school in Nepal. Kathmandu: DoE and UNICEF Nepal. 